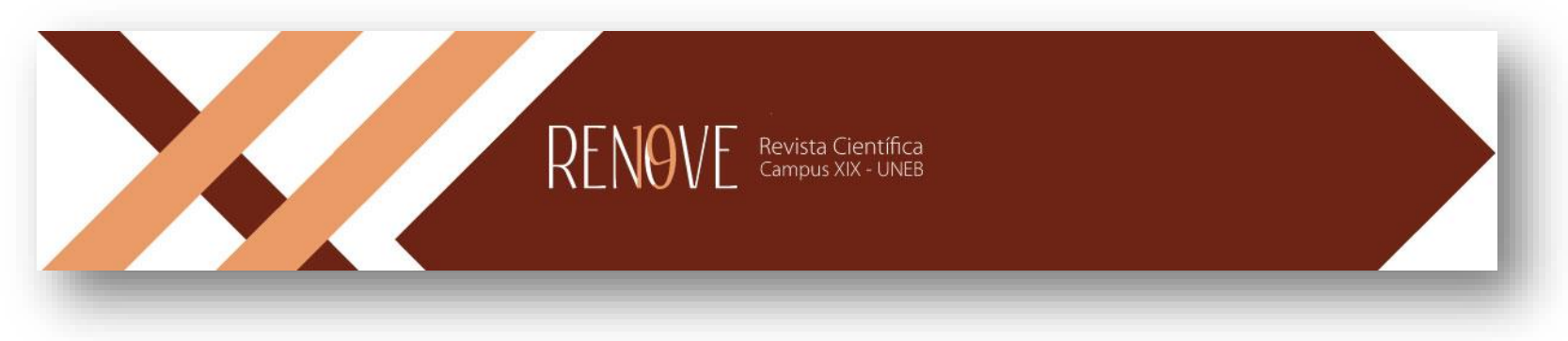

\title{
CONSTRUÇÃO DA IDENTIDADE E AUTONOMIA NA EDUCAÇÃO INFANTIL MEDIADA PELA ESCOLA E A FAMÍLIA
}

\section{CONSTRUCTION OF IDENTITY AND AUTONOMY IN CHILDHOOD EDUCATION MEDIATED BY SCHOOL AND FAMILY}

\author{
Jêime da Silva Brito Rodrigues \\ jsb.jeime@gmail.com \\ Licenciada em Pedagogia \\ Faculdade Entre Rios do Piauí-FAERPI \\ http://lattes.cnpq.br/4428412963950092
}

\section{RESUMO}

Um olhar reflexivo sobre a construção da identidade e autonomia na educação infantil possibilita a criação e o planejamento de um ambiente propício para a formação de sujeitos autônomos, críticos e com identidade própria. E para este ambiente fluir é de suma relevância a atuação dos pais e da escola para mediar este processo. Logo é essencial que a família e a escola sejam parceiras no decorrer deste processo gradual, sendo a educação infantil o principal pilar no decorrer da vida educacional, no qual esta base é suporte para a vida toda, quer seja no quesito educacional, profissional ou pessoal. Partindo do pressuposto de Como a família e escola influencia neste processo de construção da identidade e autonomia, tendo como ponto de partida a educação infantil? Em relação ao objetivo geral desta pesquisa, visa refletir sobre a influência que a família e a escola exercem perante as crianças da educação infantil, e seus reflexos durante a formação gradual da identidade e autonomia dos educandos que perpassam a vida escolar. Quanto à metodologia, foi realizada uma pesquisa bibliográfica e qualitativa, á cerca de autores que dão respaldo ao tema, em livros, revistas, artigos e consulta na internet, sobre artigos já publicados que enfatizam a relevância da temática. No que se refere aos resultados observados com a pesquisa, percebe-se que a escola e a família, são de grande relevância para a construção da identidade e autonomia dos educandos, e parceria de ambas promovem o desenvolvimento pleno da criança, a partir de ações e intervenções.

Palavras Chave: Educação Infantil. Identidade. Autonomia.

\section{ABSTRACT:}

A reflective look at the construction of identity and autonomy in early childhood education enables the creation and planning of an environment conducive to the formation of autonomous, critical subjects with their own identity. And for this environment to flow, the 
role of parents and the school to mediate this process is extremely relevant. It is therefore essential that the family and the school are partners in the course of this gradual process, with early childhood education being the main pillar throughout the educational life, in which this basis is support for life, whether in educational, professional or personal terms. . Based on the assumption of How does the family and school influence this process of building identity and autonomy, starting with early childhood education? In relation to the general objective of this research, it aims to reflect on the influence that the family and the school have on children in early childhood education, and its reflexes during the gradual formation of the identity and autonomy of the students that go through school life. As for the methodology, a bibliographic and qualitative research was carried out, about authors who support the theme, in books, magazines, articles and consultation on the Internet, about articles already published that emphasize the relevance of the theme. With regard to the results observed with the research, it is clear that the school and the family are of great relevance for the construction of the students' identity and autonomy, and the partnership of both promotes the child's full development, based on actions and interventions.

Keywords: Early Childhood Education. Identity. Autonomy.

\section{INTRODUÇÃO}

A educação Infantil é umas das etapas mais relevantes na vida escolar de um educando, configurando-se como a base inicial, que deve dar suporte para o processo de ensino e aprendizagem gradual do educando. Esta etapa educacional, também é sinônima de desenvolvimento integral da criança como um todo.

E a criança ainda conta com o suporte da família neste processo, atuando como o primeiro grupo social no qual a criança esta inserido, sendo corresponsável por grande parte do desenvolvimento integral das crianças, propiciando uma extensão que dá subsídios para a escola intensificar aquilo que o educando aprende em casa, nos vários âmbitos que abrange o desenvolvimento infantil.

Compreende-se que a escola e a família, devem ser parceiras para mediar este processo, e vários estudos e pesquisas na área da educação apontam a relações e influencias positiva de ambas no processo educacional. E essa relação saudável promove a construção da identidade e autonomia dos educandos, que por um lado tem o seio familiar como influência direta e do outro a escola, com uma atuação mais ampla, efetivando várias ações desenvolvimentistas. 
E os reflexos desses dois pilares na vida educacional de um alfabetizando, norteiam que sujeito ele será perante a sociedade inserida, tornando-se essencial para a formação de um sujeito autônomo e com sua identidade definida, discernindo aquilo que é certo e errado aos olhos da sociedade, regida por leis, regras, cultura, moral e ética própria, no qual cada individua adapta-se para conviver harmoniosamente no ambiente inserido.

Para que se almeje a formação do sujeito enquanto responsável por adquirir sua própria identidade e autonomia, é imprescindível construir ao longo de sua vida um caminho pautado no respeito mútuo relações sociais saudáveis, e tomada de decisões baseadas no espírito da

criticidade, para que esta formação aflore. É na educação infantil e na base familiar, que as primeiras possibilidades devem ser ofertadas, em um ambiente democrático e oportuniza dor, para estimular este processo.

A pesquisa partiu do pressuposto de Como a família e a escola influenciam na formação das crianças para a construção de um sujeito autônomo e com identidade própria?

No que tange ao objetivo geral desta pesquisa, visa refletir sobre a influência que a família e a escola exercem perante as crianças da educação infantil, e seus reflexos durante a formação gradual da identidade e autonomia dos educandos que perpassam a vida escolar. Quanto à metodologia, foi realizada uma pesquisa bibliográfica e qualitativa, á cerca de autores que dão respaldo ao tema, em livros, revistas, artigos e consulta na internet, sobre artigos já publicados que enfatizam a relevância da temática para a construção da identidade e a autonomia do sujeito, enfatizando a relevância da família e da escola, neste processo, tendo a educação infantil como ponto de partida.

\section{EDUCAÇÃO INFANTIL NO BRASIL E SEUS CONTEXTOS}

É notória a transição dos conceitos e contextos á cerca da criança como um ser social em nossa sociedade nos últimos anos, e também o surgimento da educação infantil como etapa essencial neste processo evolutivo. Essa transição é oriunda de debates e pesquisas, em torno da educação infantil e do direito das crianças, para refletirmos o modelo de educação infantil que temos na atualidade.

Esse olhar diferenciado na educação infantil, trilhado em caminhos pautados em meio á pesquisas e estudos sobre a criança com ser social, e que almejava por cuidados e 
atenção especial. Nunes, Corsino e Didonet (p. 13, 2011) enfatizam que: “Começa a haver, na sociedade brasileira e, especialmente, entre os especialistas da área da primeira infância, a compreensão mais generalizada da complementaridade do cuidado e da educação em cada gesto de atenção que se presta a uma criança".

De acordo com Tavares e Silva (2013, p.1):

A criança historicamente passou a ser vista como um ser social e, por conseguinte, a infância passou a serem reconhecidas juridicamente como etapa inicial da vida, para a qual é necessário respeito, instituída por uma cultura própria, por suas especificidades, suas necessidades de tratamentos e cuidados peculiares a essa fase da vida.

Visto que antigamente as crianças eram seres insignificantes na nossa sociedade e que até as políticas públicas voltadas para elas eram de caráter assistencialista, no caso do surgimento de creches, para acomodar as crianças de mães que trabalhavam fora; e os orfanatos, que recebiam crianças das mães burguesas solteiras ou de classe social inferior, que não tinham condições alguma de criar essas crianças.

Assim, relatam Paschoal e Machado (2009, p. 82) como a criança era vista, e a relação desta visão se comparado o Brasil com outros países:

Diferentemente dos países europeus, no Brasil, as primeiras tentativas de organização de creches, asilos e orfanatos surgiram com um caráter assistencialista, com o intuito de auxiliar as mulheres que trabalhavam fora de casa e as viúvas desamparadas. Outro elemento que contribuiu para o surgimento dessas instituições foram às iniciativas de acolhimento aos órfãos abandonados que, apesar do apoio da alta sociedade, tinham como finalidade esconder a vergonha da mãe solteira.

Logo, percebe-se que a família era mantedora, com o surgimento das indústrias e a necessidade da mulher de trabalhar fora, antes disso as crianças recebiam cuidados, brincavam e recebia a cultura do seio familiar, transferido posteriormente esse papel para as instituições cuidadoras, que tinha função assistencialista. A criação de creches e orfanatos tinha como objetivo essencial, criar arranjos alternativos que cuidassem das crianças pobres (SANTOS 2010).

A criação de instituições voltadas para o acolhimento de crianças, nas mais diversas conjecturas, trona-se oriunda das diversas manifestações culturais, sociais, políticas e econômicas pelo qual o Brasil perpassou nas ultimas década, em especial ate meados do século $\mathrm{XX}$, no qual os reflexos foram se esculpindo para modelar os contextos educacionais que temos na atualidade e o reconhecimento da criança e seus direitos. 
Andrade (2010, p. 134) relata a origem das instituições de atendimento infantil no Brasil:

A origem das creches no Brasil revela antecedentes do atendimento das
instituições asilares, apresentando um atendimento, até os anos 1920, de
caráter eminentemente filantrópico, destinado especialmente às mães
solteiras e viúvas que não apresentavam condições para cuidar de seus filhos.
A origem da instituição está atrelada ao desenvolvimento do capitalismo, da
industrialização e da inserção da mulher no mercado de trabalho.

De acordo com Nunes, Corsino e Didonet (2011, p. 60) há uma disparidade social inserida no campo educacional, que prevalece ainda que acanhada nos atuais, mensurando o acesso e a permanência das crianças na educação infantil: "O acesso às creches ainda é desigual entre as crianças das diferentes regiões do país; entre as da zona urbana e da rural; entre as brancas e as negras ou as pardas; e entre as de famílias mais pobres e mais ricas".

Paschoal e Machado (2009, p. 89) esclarecem a disparidade social no contexto anterior á nossa realidade: "Enquanto as instituições públicas atendiam às crianças das camadas mais populares, as propostas das particulares, de cunho pedagógico, funcionavam em meio turno, dando ênfase à socialização e à preparação para o ensino regular”.

Diante disto, percebe-se que nesta época as instituições públicas e privadas que vinham surgindo, partiam de pressupostos distintos, e que o olhar pedagógico também era diferente, sendo as crianças objeto de diferença social, politica e cultural. Kuhlmann Jr. (p. 7, 2000) complementa que: "Mas a segmentação do atendimento da criança pobre em instituições estruturadas precariamente continua na agenda dos problemas da educação infantil brasileira".

Alves (2011, p. 3) discute essa situação, ressaltando que:

Já os "jardins de infância", primeiros espaços escolares destinados às crianças pequenas de famílias mais abastadas, foram marcados pelas ideias de recreação e autonomia da criança. Concebiam a criança como uma sementinha e as professoras como "jardineiras", responsáveis por cuidar e regar a "plantinha" para que seu potencial de desenvolvimento não fosse prejudicado.

$\mathrm{Na}$ mesma linha de pensamento a respeito da disparidade social dessa época, Kuhlmann Jr. (2000 p. 8,) relata que:

A concepção da assistência científica, formulada no início do século XX, em consonância com as propostas das instituições de educação popular difundidas nos congressos e nas exposições internacionais, já previa que o 
atendimento da pobreza não deveria ser feito com grandes investimentos. A educação assistencialista promovia uma pedagogia da submissão, que pretendia preparar os pobres para aceitar a exploração social.

Nota-se que essa disparidade, incentivou as mães que trabalhavam fora e que necessitavam deixar suas crianças, a lutarem e buscar o direito das crianças, por instituições que não tivessem apenas caráter assistencialista, mas que ensinassem seus filhos, para que se desenvolvessem socialmente. Segundo Andrade (2010, p.145): “A creche passou a ser reivindicada, também, pela população de classe média, que, somada à necessidade de trabalho feminino, apresentava o reconhecimento do caráter educativo da instituição de atendimento às crianças".

De acordo com Santos (2010, p.15):

Evidentemente, a luta desencadeada pelas mulheres por creches para seus filhos intensificou o pedido pelas instituições, tanto como um direito da população como também um direito à criança de se desenvolver em um espaço adequado, que atenda às suas necessidades físicas e cognitivas, ou seja, um ambiente que complemente a educação familiar.

Neste enfoque, as mudanças á cerca dos avanços quanto aos direitos das crianças á escola, ao direito, as políticas públicas, vem se moldando para chegar aso modelo que temos na atualidade. Visto que a Educação Infantil é mola propulsora para assegurar as condições necessárias para o desenvolvimento integral, pautado em um trabalho pedagógico serio voltado para o compromisso em reconhecer a criança como cidadãos e cidadãs (TAVARES e SILVA, 2013).

Pode-se alegar que os avanços em relação aos direitos das crianças, as legislações e politicas publicas em prol do desenvolvimento integral das crianças tem tido avanços significativos na atualidade, em especial no tocante a educação no contexto brasileiro.

Parceria da Família e Escola

A escola é como se fosse uma extensão do lar dos educandos, nem a escola consegue concretizar o que de fato objetivam de cunho pedagógico, nem a família por si só, consegue avanços no rendimento escolar ou educação integral para seus filhos, ponderando-se a parceria extraordinária e promissora que é a da família e da escola na vida educacional dos alfabetizandos.

E se tratando da família, a sua relevância na formação do sujeito é imprescindível, independente das novas conjecturas e formação familiares que nos deparamos na sociedade 
moderna atual, a Família sempre será um dos pilares de suporte para a criança. Dessen e Polonia (2007, p. 22) discutem essa situação, ressaltando que:

Como primeira mediadora entre o homem e a cultura, a família constitui a unidade dinâmica das relações de cunho afetivo, social e cognitivo que estão imersas nas condições materiais, históricas e culturais de um dado grupo social. Ela é a matriz da aprendizagem humana, com significados e práticas culturais próprias que geram modelos de relação interpessoal e de construção individual e coletiva.

Santos e Toniosso (2014, p.124) relatam que: “A necessidade de encontrar caminhos que cooperam para a relação vivenciada hoje pelas escolas e famílias é evidente, diante de tantos confrontos que ambas enfrentam na construção de valores morais e éticos na conduta de jovens e adultos inseridos no contexto escolar".

Em consonância com essa parceria a delegação de papeis e responsabilidades, tornase um gargalo, mensurando de quem é cada função a cerca da educação dos educandos, envolvendo os aspectos sociais, culturais e os conhecimentos a serem transmitidos.

Daneluz (2008, p.5) acrescenta que as responsabilidades devem ter caráter mutuo e compreensível:

Tanto a família como a escola compartilham funções educativas que buscam o conhecimento e o bem estar do educando. Ambos têm a responsabilidade de apoiar o que foi decidido no outro contexto e favorecer o desenvolvimento do educando. Assim, é fundamental a participação destas famílias na escola, tanto no âmbito vinculado a gestão quanto de cunho pedagógico, na busca por oferecer estratégias para o processo de formação realmente acontecer.

À medida que a criança é matriculada na escola, percebe que a divisão das responsabilidades educacionais e de socialização do indivíduo, se entrelaçam e se divergem ao mesmo tempo, ocasionando os gargalos entre família e escola. Castro e Regattieri (2009, p. 17) afirmam que: "Parte das características fundamentais para o sucesso escolar, no entanto, não é ensinada pela ou na escola: ela deve vir como pré-requisito do aluno, desde o seu primeiro dia de aula".

Para Reis (2010, p. 17) é relevante refletir sobre:

A família tem um papel imprescindível na vida de seus filhos; é onde acontece o desenvolvimento das primeiras habilidades, os primeiros ensinamentos através da educação doméstica na qual o filho aprende a respeitar os outros, a conviver com regras que foram criadas e reformuladas no decorrer da formação da sociedade. E a escola, ela vem para reforçar esses 
valores primeiros, acrescentando, mas não assumindo para si o papel inicial da família.

$\mathrm{Na}$ perspectiva de harmonizar os conhecimentos as serem transmitidos faz-se necessário conscientizar, tanto a família como a escola quanto a sua função primordial na formação de sujeitos, sendo os pontos de referência e norte de uma pessoa.

Segundo Daneluz (2008, p.3) é essencial o engajamento da família e a escola em prol dos educandos:

A construção coletiva, a valorização da contribuição de cada um, a vivência da participação da família em todos os espaços da escola, além de garantir processos de aprendizagem, de apropriação de conhecimentos, garantirá a escolarização e poderá efetivar-se na formação de seres humanos mais bem preparados para uma prática social.

Vale ressaltar que uma relação sem conflitos entre escola e família, é algo á ser conquistado, pois várias situações impõe uma desunião entre as partes, mas que deve ser restabelecida uma confiança e parceira em prol dos educandos. Castro e Regattieri (2010, p. 36) advertem que: "Uma das principais causas diagnosticadas da fragilidade da interação das famílias com as escolas é que a maioria dos usuários do ensino público não tem a cultura de exigir educação de qualidade para seus filhos".

Neste processo, concordo com Sousa $(2012$, p.14) na seguinte consideração:

Uma das funções da escola é buscar uma aproximação com as famílias de seus alunos, pois enquanto instituição pode promover atividades como: interação e apoio com diversos profissionais como psicólogos, fazer visitas aos familiares, reuniões de pais e mestre com maior frequência, bem como a realização de trabalhos técnicos com a participação dos familiares para que estes possam conhecer os conteúdos que seus filhos estão desenvolvendo nas diversas atividades curriculares, proporcionando ligação entre escolafamília- professores.

Evidentemente, muitos pais abstêm-se da vida escolar do filho, pela correria do cotidiano, onde os membros da família trabalham fora, em especial as mães que são a principal provedora do processo educacional das crianças, no que tange a educação e socialização baseada no seio familiar. E a relação estreita entre família e escola restringe a pequenos ou eventuais encontros anuais ou semestrais.

Oliveira (2010, p. 15) relata que: 
Em inúmeras circunstâncias a participação dos pais na escola acontece na forma de reunião geral ou de turma, conversa informal, troca de palavras à saída da escola, encontro na escola ou noutro lugar, organização de festas, espectáculos, convívios, visitas de estudo... Alguns destes contactos acontecem ora por iniciativa dos pais ora por iniciativa dos professores.

Também é importante considerar que a família deve estar a par da vida escolar de seus filhos e arcar com as responsabilidades que a ela é cabível, tornando-se um cumplice na educação de seus filhos e não fazer intrigas com a escola, repassando uma para outra a sua responsabilidade. Os pais devem ser atuantes na educação de seus filhos, uma vez que vida escolar e vida familiar andam paralelamente juntas, cabendo aos pais juntamente com professores e os educandos, compartilharem experiências e lidar com situações juntos, para compreenderem uns aos outros sem julgamentos de culpa (REIS, 2010).

Para viabilizar o relacionamento harmonioso entre família e escola, é interessante que as partes partam de um mesmo princípio, que é a educação das crianças como prioridade básica e que façam com respeito, amor e responsabilidade, pautadas no afeto e nas ações oportunizadas de um ambiente tranquilo favorecer a adsorção de conhecimentos, ações essas que são essenciais para o processo de ensino-aprendizagem dos educandos.

\section{Construção da Identidade e Autonomia na Educação Infantil}

A sociedade no qual estamos inseridos é norteada por um mix de cultura, religiões, costumes, moral, etnias, classes sócias, ética. E em síntese, com o advento da globalização e a predominâncias desses aspectos, nos traz a reflexão de como agir e como conviver em meio às diferenças, políticas, sociais, econômicas e culturais do nosso país.

Avila (2008, p. 9) discute essa situação, ressaltando que:

Nos primeiro momentos de vida somos inseridos em uma determinada sociedade, com diferentes éticos e morais, rica em diversidade cultural e ética, isso nos torna seres sociais. É nesse processo de socialização, no qual permaneceremos por toda a vida, e que irá se dar a construção de nossa identidade que envolve a subjetividade de cada um, a singularidade, um jeito único de formação do ser. Esse processo acontece de modo gradativo, dentro da sociedade que estamos inseridos.

Nota-se que, a autonomia também é parte da vida do sujeito em sociedade, que tem nas suas relações sociais as primeiras ramificações do individuo autônomo e crítico, capazes 
de fazer suas próprias escolas e responder por seus atos, tendo sua personalidade e identidade, auferidos pelo meio social inserido.

Dias (2005, p. 371) adverte que:

O sujeito autônomo, enquanto protagonista de condutas morais, não se constitui de forma isolada, independentemente das condições sociais, históricas, políticas, econômicas e culturais. Ao contrário, define-se como aquela que, dialógica e dialeticamente, é capaz de articular, de forma crítica e ativa, vontade subjetiva (individual e pessoal) e vontade objetiva ( instituições sociais e cultura), questionando, refletindo, respondendo, influenciando e sendo influenciado pela ocorrências do seu ambiente, construindo e reconstruindo dinamicamente as experiências que vive tanto no plano individual quanto coletivamente.

Logo, percebe-se que a identidade e autonomia, moldam a personalidade e caráter das crianças desde os anos iniciais de sua vida, tendo as relações sócias como fonte norteadora. Avila (2008, p. 23) lembra que: "Cada individuo evolui em um determinado tempo. Cada criança tem o seu próprio processo de construção da autonomia".

E encontra-se em meio à adversidade torna-se um desafio, saber qual a sua origem, seus princípios, estabelecer sua identidade e ser coadjuvante de suas ações, além de ter sua autonomia e liberdade de expressão nos dias atuais, que de um lado vive no preconceito, e por outro adere á modernidade, perdendo alguns valores intrínsecos á sociedade inserida.

O RCNEI (1998, p. 13) define identidade como:

\begin{abstract}
A identidade é um conceito do qual faz parte a ideia de distinção, de uma marca de diferença entre as pessoas, a começar pelo nome, seguido de todas as características físicas, de modos de agir e de pensar e da história pessoal. Sua construção é gradativa e se dá por meio de interações sociais estabelecidas pela criança, nas quais ela, alternadamente, imita e se funde com o outro para diferenciar-se dele em seguida, muitas vezes utilizando-se da oposição.
\end{abstract}

Pensamento em que trás a temática identidade e autonomia como foco, e para tal faz necessário compreende que é a partir da educação infantil que se dá o processo de construção da identidade e autonomia de um sujeito. Dessa forma, Souza, Silva e Melo (2012, p. 2) 
afirmam que: "Identidade, autonomia e diversidade são termos muito atuais e utilizados entre os professores, gestores, equipe técnica e até mesmo entre a família, pessoas que se preocupam com a educação e no desenvolvimento infantil”.

De acordo com o RCNEI (1998, p. 11):

O desenvolvimento da identidade e da autonomia estão intimamente relacionados com os processos de socialização. Nas interações sociais se dá a ampliação dos laços afetivos que as crianças podem estabelecer com as outras crianças e com os adultos, contribuindo para que o reconhecimento do outro e a constatação das diferenças entre as pessoas sejam valorizadas e aproveitadas para o enriquecimento de si próprias.

Em decorrência desse processo construtivo da autonomia e da identidade a escola e a família constitui-se como base norteadora neste processo, cada uma com sua parcela de contribuição, e que na totalidade são premissa básica de uma construção mutua para toda a vida do sujeito. Para Moura, Viana e Loyola (2013, p. 487): “O relacionamento entre pais e filhos é essencial em relação ao processo gradativo de autonomia da criança e às influências de seu meio social”.

Araújo e Leite (2015, p. 02) destacam que:

Sabe-se que as crianças precisam ter oportunidade de fazer suas escolhas, de se responsabilizarem por suas tarefas, de exercerem, enfim, sua independência, assumindo conscientemente seus direitos e deveres. Para a criança, é muito mais significativo aprender através de situações que a incentivem a fazer sozinha, já que muito antes do que supomos a criança já é capaz de assumir responsabilidades, aceitar deveres e usar sua própria iniciativa, constituindo-se esta na única maneira de ela tornar-se cada vez mais autossuficiente e independente.

Neste sentido, Pereira (2006, p. 4) relata sobre o papel da escola como ponte mediadora da evolução autônoma da criança: “A autonomia é um termo frequentemente utilizado pelos pais e educadores que se preocupam com a educação e o desenvolvimento infantil. No Contexto educacional, a autonomia é um tema fundamental, alicerçando-se na ideia de Jean Piaget de que esta se constitui um fim da educação". 
Vale ressaltar que a escola também é de suma relevância, como parte integralizada desse processo construtivo, no qual os educando devem ser oportunizados no desenvolvimento da identidade e autonomia, com foco nas próprias escolhas e com ações planejadas e dirigidas por parte da escola, tendo a escola como parceira e parte proficiente neste processo.

\section{CONSIDERAÇÕES FINAIS}

As Transformações no campo educacional, no que tange a inserção da educação infantil como etapa primordial, paulatinamente tornando-se a base sólida para o sucesso educacional e social do educando, são fonte de muitos estudos e pesquisas sobre essa temática e que vários aspectos desde sociais, políticos, culturais e econômicos, alavancam essas transformações, que há década foram introduzidas no Brasil com objetivos distintos, e que nos dias atuais modelam-se no modelo educacional que a educação infantil tem aderido.

Em decorrência dessas transformações a criança ganha espaço e direitos na sociedade, no qual é vista como um ser social, e que a garantia desses direitos são efetivadas por leis, estatutos e políticas públicas. Pautadas na afetividade e no apoio familiar aliado ao apoio escolar, como subsídios para o desenvolvimento integral do educando, formando sujeitos para uma vida em sociedade.

Logo, percebe-se que esse novo olhar em relação à criança e a educação infantil no Brasil acarretam pontos positivos, no qual a criança aprende mais, principalmente quando a família é presente na vida escolar dos filhos, estabelecendo uma parceria promissora entre família e escola. Esta parceria tem caráter completar, pois os educando potencializam na escola aquilo que teve como premissa básica o seio familiar, cuja valorização de seus costumes, moral, cultura deve ser respeitada pela escola.

Por fim, quanto á continuidade de pesquisas nesta linha de estudo, recomenda-se, uma pesquisa na área de Orientações Curriculares para o Eixo Identidade e Autonomia na Educação Infantil, como foco pelo exposto, pode-se concluir que a parceria da família e a escola é fator primordial para o sucesso escolar, e que as duas entidades juntas são o suporte para a efetivação eficiente do processo de ensino-aprendizagem, bem como no desenvolvimento integral dos educando. 
É relevante salientar, que a construção da autonomia e da identidade dos alfabetizandos, perpetua mediante os estímulos oriundos da parceria harmoniosa entre família e escola, tendo o educando como o elo mais importante desta cadeia educacional. E que a conscientização das responsabilidades, torna essa relação fortalecida, e seus reflexos são nítidos na aquisição da autonomia e identidade dos educando, sendo a família e a escola, as referências básicas e ativas neste processo construtivo.

\section{REFERÊNCIAS}

ALVES, Bruna Molisani Ferreira. Infâncias e Educação Infantil: Aspectos Históricos, Legais e Pedagógicos. Revista Aleph Infâncias, Ano V, No 16, Novembro, 2011.

ANDRADE, Lucimary Bernabé Pedrosa de. Educação Infantil: Discurso, Legislação e Práticas Institucionais. Editora UNESP; São Paulo: Cultura Acadêmica, 2010. 193 p. Disponível em: http://books.scielo.org. Acessado em: Dezembro de 2016.

AVILA, Myriam Sela Jayme. A Identidade e Autonomia em Construção na Educação Infantil. São Paulo, 2008.

ARAÚJO, Elaine Patrícia; LEITE, Maria Elizabete. Desenvolvimento da Autonomia Infantil em uma Creche Municipal de Ensino de Campina Grande-Pb. Revista Acadêmica Científica Scire, Vol. 08 - Num. 02 - Agosto 2015. Disponível em: www.revistascire.com.br. Acessado em Fevereiro de 2017.

CASTRO, Jane Margareth; REGATTIERI, Marilza. Interação Escola-Família: Subsídios para Práticas Escolares. Brasília: UNESCO, MEC, 104 p., 2009.

DANELUZ, Mariluci. Escola e Família - Duas Realidades, um mesmo Objetivo. I Simpósio Nacional de Educação. XX Semana da Pedagogia. Unioeste-Paraná, Novembro de 2008.

DESSEN, Maria Auxiliadora; POLONIA, Ana da Costa. A Família e a Escola como Contextos de Desenvolvimento Humano. Universidade de Brasília, Distrito Federal, Brasil, p. 21-32, 2007, Disponível em: www.scielo.br/paideia. Acessado em: Janeiro de 2017.

DIAS, Adelaide Alves. Educação Moral e Autonomia na Educação Infantil: o que Pensam os Professores. Psicologia: Reflexão e Crítica, p. 370-380, Paraíba, 2005.

KUHLMANN JR, Moysés. Histórias da Educação Infantil Brasileira. Revista Brasileira de Educação, Mai/Jun/Jul/Ago, 2000, Nº 14.

MOURA, Tiago Bastos de; VIANA, Flávio Torrecilas; LOYOLA, Viviane Dias. Uma Análise de Concepções Sobre a Criança e a Inserção da Infância no Consumismo. Psicologia: Ciência e Profissão, p. 474-489, Belo Horizonte-MG, 2013. 
NUNES, Maria Fernanda Rezende; CORSINO, Patrícia; DIDONET, Vital. Educação Infantil no Brasil: Primeira Etapa da Educação Básica. Brasília: UNESCO, Ministério da Educação/Secretaria de Educação Básica, Fundação Orsa, 102 p., 2011.

PASCHOAL, Jaqueline Delgado; MACHADO, Maria Cristina Gomes. A História da Educação Infantil no Brasil: Avanços, Retrocessos e Desafios dessa Modalidade Educacional. Revista HISTEDBR On-line, Campinas, n.33, p.78-95, mar.2009. Disponível em: http://periodicos.sbu.unicamp.br/ojs/index.php/histedbr. Acessado em: Dezembro de 2016.

PEREIRA, Regiane Larréa. O Papel da Educação Infantil na Construção da Autonomia Moral: uma Revisão de Literatura. Porto Alegre, Março de 2006.

OLIVEIRA, Maria do Céu Gomes Leal de. Relação Família-Escola e Participação dos Pais. Porto, Setembro de 2010.

RCNEI. Referencial Curricular Nacional para a Educação Infantil / Ministério da Educação e do Desporto, Secretaria de Educação Fundamental. — Brasília: MEC/SEF, Volume 2, 1998.

REIS, Liliani Pereira Costa dos. A Participação da Família no Contexto Escolar. Salvador, 2010 .

SANTOS, Nathalia Fernanda Ribeiro Dos. Educação Infantil no Brasil: O Paradigma entre e Cuidar e o Educar no Centro de Educação Infantil. Londrina, 2010.

SANTOS, Luana Rocha dos; TONIOSSO, José Pedro. A importância da relação escolafamília. Cadernos de Educação: Ensino e Sociedade, Bebedouro-SP, p.122-134, 2014.

SOUSA, Jacqueline Pereira De. A Importância da Família no Processo de Desenvolvimento da Aprendizagem da Criança. Fortaleza, 2012.

SOUZA, Patrícia da Silva; SILVA, Kátia Anne Bezerra da; MELO, Margareth Maria de. Afrobrasilidade na Educação Infantil: um Olhar Pedagógico á Diversidade. Campina Grande, REALIZE Editora, 2012.

TAVARES, Keilla Mara Soares; SILVA, Rita de Cássia Melém Da. Currículo na Educação Infantil: um Diálogo Entre Propostas e Práticas. Revista do Difere, v. 3, n.5, jun/2013. 